\title{
Immobilization of Organic Functional Groups onto Silica
}

Polymer-Supported Synthesis

Key words

dimethyldivinyl-

silane

transition-metal catalysis

surface

modification<smiles>C=CN(C)O[As](C)(=O)=O</smiles>

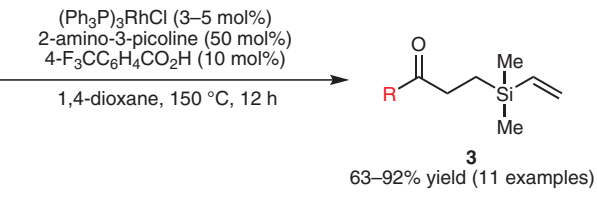
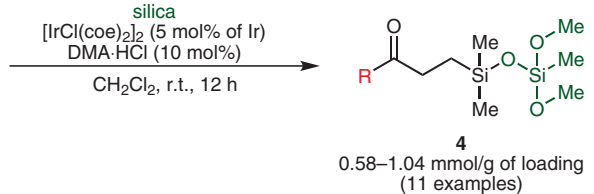

silica

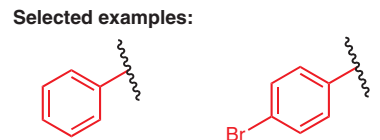<smiles>CC(C)(C)c1ccc(B2OC(C)(C)C(C)(C)O2)cc1</smiles><smiles>CCc1ccc(C(=O)O)cc1</smiles>

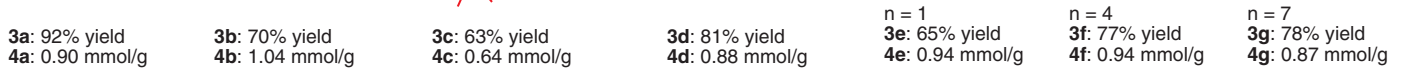

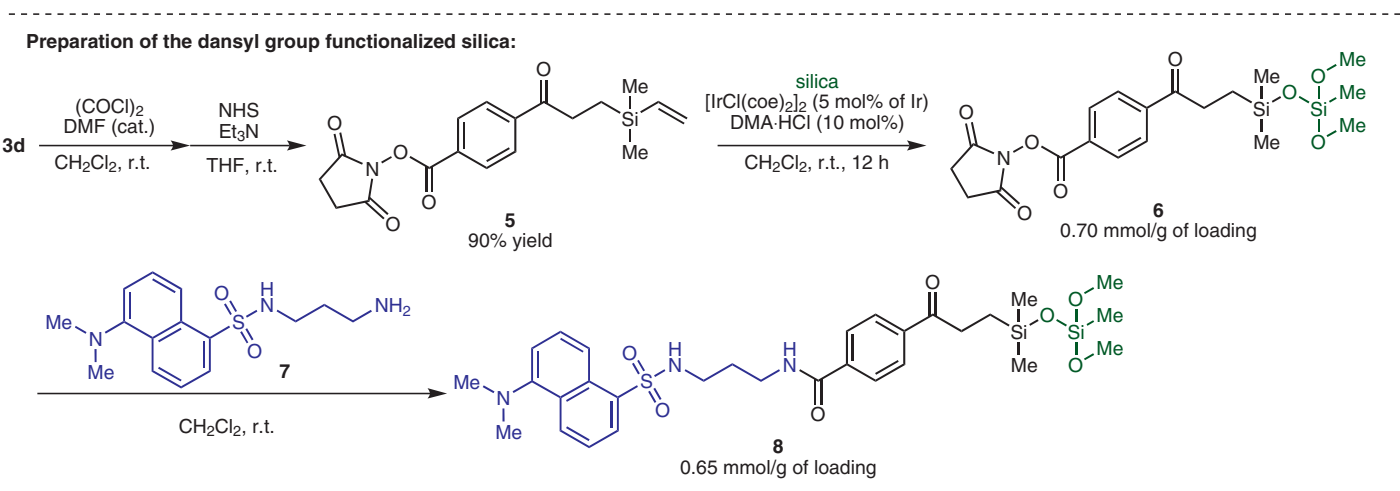

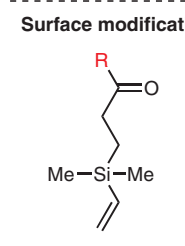

3e $\left(\mathrm{R}=n-\mathrm{C}_{3} \mathrm{H}_{7}\right)$ 3f $\left(\mathrm{R}=n-\mathrm{C}_{6} \mathrm{H}_{13}\right)$ $\mathbf{3 g}\left(\mathrm{R}=n-\mathrm{C}_{9} \mathrm{H}_{19}\right)$

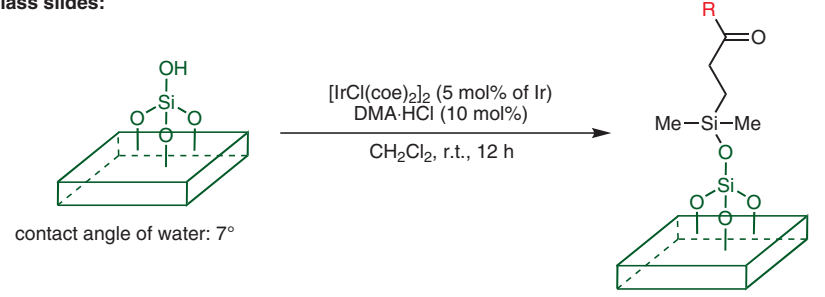

contact angle of water:

$71^{\circ}\left(9 e, \mathrm{R}=n-\mathrm{C}_{3} \mathrm{H}_{7}\right)$

$81^{\circ}\left(9 \mathrm{~g}, \mathrm{R}=n-\mathrm{C}_{6} \mathrm{H}_{13}\right)$

$94^{\circ}\left(9 \mathrm{~g}, \mathrm{R}=n-\mathrm{C}_{9} \mathrm{H}_{19}\right)$
Significance: Functionalized vinylsilanes $\mathbf{3}$ were prepared by hydroacylation of dimethyldivinylsilane (2) with various aldehydes $\mathbf{1}$ in the presence of $\left(\mathrm{Ph}_{3} \mathrm{P}\right)_{3} \mathrm{RhCl}$, 2-amino-3-picoline, and 4-(trifluoromethyl)benzoic acid (63-92\% yield, 11 examples). Immobilization of $\mathbf{3}$ onto silica by using $\left[\mathrm{IrCl}(\mathrm{COe})_{2}\right]_{2}$ and DMA. $\mathrm{HCl}$ gave the corresponding functionalized silica compounds 4 with 0.58-1.04 $\mathrm{mmol} / \mathrm{g}$ of loading (11 examples).

synfacts Contributors: Yasuhiro Uozumi, Yoichi M. A. Yamada, Toshihiro Watanabe Synfacts 2010, 9, 1077-1077 Published online: 23.08.2010 DOI: 10.1055/s-0030-1257987; Reg-No.: Y09210SF
Comment: The silica-immobilization method $\left\{\left[\mathrm{IrCl}(\mathrm{COe})_{2}\right]_{2} ; \mathrm{DMA} \cdot \mathrm{HCl}\right\}$ has been developed by the same authors (Org. Lett. 2007, 9, 4073). Surface modification of hydrophilic glass slides with vinylsilanes $\mathbf{3 e}-\mathbf{g}$ gave the significantly hydrophobic glass slides $\mathbf{9 e -} \mathbf{- g}$ as estimated from contact angle measurements. 